\title{
TESTE DE COMPRIMENTO DE PLÂNTULAS SOB ESTRESSE HÍDRICO NAAVALIAÇÃO DO POTENCIAL FISIOLÓGICO DAS SEMENTES DE MILHO ${ }^{1}$
}

\author{
MARIZANGELARIZZATTIÁVILA ${ }^{2}$, ALESSANDRO DE LUCCAE BRACCINI ${ }^{3}$, CARLOSALBERTO SCAPIM ${ }^{3}$
}

\begin{abstract}
RESUMO - O presente trabalho teve por objetivo avaliar a eficiência do teste de comprimento das plântulas sob estresse hídrico na avaliação do potencial fisiológico das sementes de milho e verificar sua relação com a emergência das plântulas em campo. Para isso, sementes de milho provenientes de cinco lotes comerciais foram avaliadas por meio dos testes de germinação (primeira e ultima contagem), envelhecimento acelerado, frio modificado, condutividade elétrica, emergência das plântulas em campo e comprimento das plântulas sob estresse hídrico, utilizando diferentes níveis de potencial osmótico ( 0 ; -0,1; -0,3; -0,6 e -0,9MPa) em solução de manitol. Há uma correlação significativa e positiva entre o teste de comprimento de plântulas sob estresse hídrico e a emergência das plântulas em campo e o teste de comprimento das plântulas sob estresse hídrico a -0,9MPa é o mais eficiente para avaliar o potencial fisiológico de sementes de milho.
\end{abstract}

Termos para indexação: Zea mays, germinação, vigor, potencial osmótico

\section{SEEDLING LENGTHTEST UNDER WATER STRESS ON THE EVALUATION OFTHE PHYSIOLOGICAL POTENTIAL OF CORN SEEDS}

\begin{abstract}
The present study was carried out with the aim of evaluating the efficiency of the seedling length test under water stress in the evaluation of the physiological potential of corn seeds and verifying its relation with seedling emergence in the field. For this reason, corn seeds from five commercial lots were evaluated by means of the germination test (first count and final count), accelerated aging, modified cold, electrical conductivity, seedling emergence in the field and seedling length test under water stress, using different levels of osmotic potential $(0 ;-0.1 ;-0.3$; -0.6 and $-0.9 \mathrm{MPa}$ ) in manitol solution. There was a significant and positive correletionship between the seedling length test under water stress and emergence in the field and the seedling length test under water stress to -0.9MPa was the best to evaluate the physiological potential of corn seeds.
\end{abstract}

Index terms: Zea mays, germination, vigor, osmotic potential

\section{INTRODUÇÃO}

A avaliação da qualidade fisiológica de um lote de semente é realizada principalmente pelo teste de germinação que proporciona uma estimativa da qualidade do lote de sementes sob condições ideais.

Contudo a validade deste teste para predizer o comportamento das sementes no campo, onde as condições ideais do ambiente dificilmente ocorrem, estando as sementes sujeitas às situações adversas, de forma que a porcentagem de emergência de plântulas no campo é geralmente menor

\footnotetext{
${ }^{1}$ Submetido em 25/09/2005. Aceito para publicação em 07/03/2007.

${ }^{2}$ Eng. Agrônoma, Dr., Prof. Adjunta do Depto. de Agronomia, UEM, Maringá, PR, Av. Colombo, 5790, Maringá, PR, CEP 87020-900; Bolsista da
}

que a obtida no teste de germinação é questionada por Byrum e Copeland (1995).

A constatação da inadequação do teste de germinação para estimar a emergência das plântulas em campo, sob condições adversas do ambiente, estimulou o desenvolvimento de conceitos de vigor e novos testes foram desenvolvidos para aumentar a eficiência da avaliação da qualidade das sementes (McDonald Junior e Wilson, 1979).

Os testes de vigor têm como objetivos básicos avaliar ou detectar diferenças significativas na qualidade fisiológica dos lotes com germinação semelhante, distinguir lotes de

CAPES; marizangela_rizzatti@hotmail.com

${ }^{3}$ Eng. Agrônomo, Dr., Prof. Associado do Depto. de Agronomia, UEM, Maringá, PR; Bolsista do CNPq; albraccini@uol.com.br; cascapim@uem.br 
elevado com os de baixo vigor e separar lotes em diferentes níveis de vigor, de maneira proporcional ao comportamento quanto à emergência das plântulas, resistência ao transporte e potencial de armazenamento e, os testes de vigor têm sido amplamente utilizados nos programas de controle de qualidade da semente (Marcos Filho, 1999a).

A escolha do método de avaliação do vigor das sementes deve observar o atendimento dos quesitos de rapidez, objetividade, simplicidade, economia e reprodutibilidade, além de permitir a interseção dos dados obtidos em diferentes testes (Caliari e Silva, 2001). O uso de diversos testes ganha importância à medida que, dependendo dos métodos utilizados, as informações obtidas possam ser distintas entre si e os testes de vigor estão sendo executados, procurando comparar, com precisão, o comportamento de lotes de sementes em laboratório e no campo (Marcos Filho et al., 1984).

O teste de frio é, provavelmente, o método mais utilizado para avaliar o vigor de sementes de milho. Embora existam diversos trabalhos empregando este teste para avaliação da qualidade fisiológica com sementes de outras espécies, os estudos com relação aos aspectos metodológicos e sua utilização se concentram em sementes de milho (Barros et al., 1999).

Um dos testes mais utilizados para a avaliação do vigor é o de envelhecimento acelerado (Ferguson-Spears, 1995), que se baseia no aumento da deterioração das sementes, quando expostas a condições adversas de alta temperatura e alta umidade relativa.

O teste de condutividade elétrica é um método rápido e prático. O vigor das sementes é avaliado indiretamente comparando-se os valores das leituras da quantidade de lixiviados liberados internamente da semente para a solução de embebição.

O teste de emergência das plântulas em campo, também denominado de população inicial ou estande inicial, visa determinar o vigor do lote de sementes, avaliando a porcentagem de emergência de plântulas em condições de campo.

Os testes baseados no desempenho ou características de plântulas como a primeira contagem da germinação, onde é avaliada a porcentagem de plântulas normais que são obtidas por ocasião da primeira contagem do teste de germinação na amostra em análise e comprimento de plântulas, são eficientes para determinar o vigor das sementes (Nakagawa, 1999).

Dentre os vários procedimentos utilizados na determinação do vigor, umas das alternativas seria submeter sementes ao estresse osmótico em condições de laboratório, uma vez que sementes com maior vigor seriam mais tolerantes às condições de estresse criadas no substrato (Santos et al., 1996 e Piana e Silva, 1998). Young et al. (1983) observaram que em condições de estresse de água o crescimento das plântulas, em termos de comprimento e espessura são reduzidos o que foi comprovado por Silva (1989), onde a baixa disponibilidade de água reduziu o comprimento das plântulas de milho. Emmerich e Hardegree (1991) e Germu e Naylor (1991) mencionam que, de maneira geral, a redução progressiva do potencial hídrico do substrato provoca decréscimo no comprimento das plântulas e na porcentagem de germinação. De acordo com Mathews e Powell (1986), em termos gerais, menor qualidade fisiológica tem sido associada aos piores desempenhos nessa condição.

Em laboratório, situações de estresse hídrico podem ser simuladas utilizando-se diversas soluções osmóticas. Dentre estas, pode-se citar o polietileno glicol [HOCH2 (6CH2CH2) $\mathrm{N} \mathrm{OH}$, o manitol $\left(\mathrm{C}_{6} \mathrm{H}_{14} \mathrm{O}_{6}\right)$, o cloreto de cálcio $\left(\mathrm{CaCl}_{2}\right)$, o cloreto de potássio $(\mathrm{KCl})$ e o cloreto de sódio $(\mathrm{NaCl})$. Quantidades específicas, para cada um destes agentes osmóticos, simulam um determinado potencial osmótico e estes potenciais podem ser estabelecidos pela equação de Van't Hoff (Souza e Cardoso, 2000).

Manitol e polietileno glicol têm sido comumente utilizados como agentes osmóticos para simular condições de déficit hídrico, porque são compostos quimicamente inertes e não tóxicos (Parmar e Moore,1968), contudo Slavik (1974) considerou que o manitol, um álcool hexanídrico, pode penetrar nas sementes durante a germinação, mostrando inclusive fitotoxicidade. Machado Neto et al (2006) verificaram que as soluções osmóticas de manitol podem ser usadas como simuladores de deficiência hídrica, no potencial de até -0,6MPa em sementes de feijão, da mesma forma, Braccini et al. (1996b), verificaram que o uso de solução de manitol para simular condições de baixa umidade no solo apresentou resultados satisfatórios com sementes de soja.

Dessa forma, o objetivo do presente trabalho foi verificar a possibilidade da utilização do teste de comprimento das plântulas sob estresse hídrico como alternativa para a avaliação do potencial fisiológico de sementes de milho, bem como verificar sua correlação com a emergência das plântulas em campo.

\section{MATERIAL E MÉTODOS}

O presente trabalho foi conduzido no Laboratório de Tecnologia de Sementes situado no Núcleo de Pesquisas 
Aplicadas à Agricultura (NUPAGRI) e na Fazenda Experimental de Iguatemi (FEI), ambos pertencentes ao Centro de Ciências Agrárias da Universidade Estadual de Maringá. Foram utilizadas sementes de milho provenientes de cinco lotes comerciais, em que cada lote constituiu-se de um híbrido. A avaliação da qualidade fisiológica das sementes de milho foi realizada pelo teste de germinação, primeira contagem da germinação, envelhecimento acelerado, frio modificado, condutividade elétrica, emergência das plântulas em campo e comprimento das plântulas sob estresse hídrico, utilizando diferentes níveis de potencial osmótico ( 0 ; -0,1; -0,3; -0,6 e -0,9MPa) em solução de manitol. Os referidos testes são descritos a seguir.

Teste de germinação: conduzido com dezesseis repetições de 50 sementes para cada lote, colocadas para germinar entre três folhas de papel-toalha embebidas com água destilada na proporção de 2,5 vezes o peso do papel seco. Foram confeccionados rolos, sendo estes levados para um germinador do tipo "Mangelsdorf”, regulado para manter constante a temperatura de $25^{\circ} \mathrm{C}$. As avaliações foram realizadas aos quatro (primeira contagem) e sete dias (contagem final), computando-se a porcentagem de plântulas normais, segundo os critérios estabelecidos pela Regras para Análise de Sementes (Brasil, 1992).

Primeira contagem do teste de germinação: efetuada em conjunto com o teste de geminação, utilizando-se a mesma metodologia, computando-se a porcentagem de plântulas normais obtidas no quarto dia após a semeadura (Brasil, 1992).

Envelhecimento acelerado: realizado utilizando-se caixa plástica do tipo "gerbox" com tela metálica cujo interior, abaixo da tela, foi adicionado 40ml de água destilada para formar uma câmara úmida. Cada “gerbox" foi considerado um compartimento individual, onde acondicionou-se uma amostra de $40 \mathrm{~g}$ das sementes de cada lote de milho, de modo a formar uma camada uniforme, tomando toda a superfície da tela metálica, deixando as sementes à distância de aproximadamente $2 \mathrm{~cm}$ do nível superior da lâmina de água. Posteriormente a este procedimento, todas as caixas foram fechadas, lacradas com fita crepe, permanecendo em uma estufa incubadora do tipo B.O.D., regulada para manter constante a temperatura de $42^{\circ} \mathrm{C}$, durante um período de envelhecimento de 96 horas. Vencido este período, as sementes foram submetidas ao teste padrão de germinação, conforme descrito anteriormente, e a avaliação realizada ao final do quarto dia após a semeadura, computando-se as plântulas consideradas normais (Marcos Filho, 1999b).

Teste de frio modificado: conduzido com dezesseis repetições de 50 sementes para cada lote. Como substrato, foram utilizadas três folhas de papel-toalha, umedecidas com água destilada. Após a semeadura, confeccionou-se rolos, sendo estes envoltos por sacos plásticos lacrados com fitas adesivas, permanecendo nesta condição por um período de sete dias em uma câmara de germinação do tipo B.O.D, regulada à temperatura constante de $10^{\circ} \mathrm{C}$. Em seguida, os rolos foram levados para um germinador regulado para manter constante a temperatura de $25^{\circ} \mathrm{C}$, durante sete dias, procedendo-se em seguida a avaliação. Os resultados foram expressos em porcentagem de plântulas normais obtidas na data de avaliação, segundo os critérios adotados para o teste de germinação (Brasil, 1992).

Condutividade elétrica: avaliada utilizando-se dezesseis repetições de 50 sementes para cada lote. Inicialmente, as sementes foram pesadas, eliminando-se as com trincas e/ou fraturas, mesmo as superficiais. Posteriormente, foram pesadas e colocadas em copos plásticos contendo $75 \mathrm{ml}$ de água deionizada, então, levadas para uma estufa incubadora regulada à temperatura de $25^{\circ} \mathrm{C}$, por um período de 24 horas. Ao final desse período, efetivou-se a leitura da condutividade elétrica na solução de embebição utilizando-se um condutivímetro microprocessado digital de bancada, modelo ACA 150, da marca Alpax. Previamente à leitura, a solução de embebição foi levemente agitada com a ajuda de um bastão de vidro. O eletrodo do aparelho foi lavado em água desmineralizada e seco com papel toalha antes de cada medição. O valor indicado pelo aparelho foi anotado e dividido pelo peso obtido de cada repetição. Desse modo, o resultado obtido foi expresso em ìs $\mathrm{cm}^{-1} \mathrm{~g}^{-1}$ (Vieira e Krzyzanowski, 1999).

Emergência das plântulas em campo: conduzida com dezesseis repetições de 100 sementes para cada lote, distribuídas em sulcos com 1,0m de comprimento. A profundidade de instalação foi de, aproximadamente $3,0 \mathrm{~cm}$ e o espaçamento entre linhas de $0,5 \mathrm{~m}$. A leitura foi feita aos 21 dias após a semeadura, computando-se as plântulas emergidas (Nakagawa, 1994).

Comprimento das plântulas sob estresse hídrico: conduzido com níveis de potencial osmótico de 0 (controle); $-0,1 ;-0,3 ;-0,6$ e -0,9MPa, obtidos em soluções aquosas de manitol. As concentrações de manitol utilizadas para obtenção dos diferentes níveis de potencial osmótico foram calculadas pela fórmula de Van’t Hoff (Hillel, 1971), ou seja:

$\mathrm{Y}_{\text {os }}=-\mathrm{RTC}$, em que: $\mathrm{Y}_{\text {os }}=$ potencial osmótico (atm); $\mathrm{C}=$ concentração (mol L-1 $) ; \mathrm{T}=$ temperatura $(\mathrm{K}) ; \mathrm{R}=$ constante geral dos gases perfeitos $\left(0,082 \mathrm{~atm} \mathrm{~L}^{-1} \mathrm{~mol}^{-1} \mathrm{~K}^{-1}\right)$.

Foram utilizadas dezesseis repetições de vinte sementes 
para cada lote, distribuídas entre três folhas de papel-toalha (embebidas com as soluções de manitol, nos diferentes níveis de potencial osmótico para se obter as tensões de água desejadas no umedecimento do papel) e semeadas eqüidistantes sobre um terço horizontal demarcado no limite do terço superior, sendo posteriormente confeccionados rolos. Estes foram embalados em sacos plásticos de coloração preta com a finalidade de manter constante a umidade no seu interior, bem como eliminar o efeito da luminosidade, sendo levados para um germinador tipo Mangelsdorf, onde permaneceram à temperatura constante de $25^{\circ} \mathrm{C}$, por um período de sete dias. A quantidade da solução aplicada no substrato foi equivalente a 2,5 vezes o peso do papel seco. $O$ comprimento das plântulas consideradas normais (Brasil, 1992) foi determinado ao final do sétimo dia, com o auxílio de régua milimetrada. Os resultados foram expressos em porcentagem de plântulas normais.

Delineamento experimental e análise estatística

Para os testes conduzidos em laboratório, o delineamento experimental adotado foi o inteiramente casualizado com dezesseis repetições e para o teste de emergência das plântulas em campo utilizou-se o delineamento em blocos completos casualizados com quatro repetições. Os dados obtidos foram submetidos à análise de variância e as médias foram comparadas pelo teste de agrupamento de Scott-Knott (1974), a 5\% de probabilidade. Para a avaliação do comprimento das plântulas sob estresse hídrico, realizou-se análise de regressão, para cada lote em função dos níveis de potencial osmótico testados, porém não foram possíveis ajustes matemáticos.

Calcularam-se também os coeficientes de correlação simples de Pearson (r) para todas as combinações entre os testes de avaliação da qualidade fisiológica das sementes a $5 \%$ de probabilidade.

\section{RESULTADOS E DISCUSSÃO}

A baixa precipitação registrada no período de condução do experimento, 49mm, pode ter influenciado diretamente nos resultados do teste de emergência das plântulas no campo, os quais demonstraram que o lote 1 apresentou maior emergência; enquanto que a emergência das plântulas dos lotes 2, 3 e 4 foi intermediária e o lote 5 foi o que apresentou pior emergência das plântulas em campo. A habilidade de uma semente germinar sob amplo limite de condições é definida como a manifestação de seu vigor, dependendo, entre outros fatores, das condições ambientais encontradas no local onde foi semeada.

Pelos resultados do teste de germinação (Tabela 1), os lotes 1, 4 e 5 apresentaram maior porcentagem de germinação, ou seja, foram os lotes que apresentaram melhor qualidade fisiológica, enquanto que os lotes 2 e 3 apresentaram menor porcentagem de germinação no referido teste, sendo considerados os de qualidade fisiológica inferior; estes resultados não estão de acordo com os obtidos para a emergência das plântulas no campo, o que já era esperado, haja visto que o teste de germinação não tem sido adequado para expressar o real comportamento das sementes em condição de campo, muito embora seja considerado um teste imprescindível na fiscalização do comércio de sementes (McDonald, 1993).

Na primeira contagem de germinação (Tabela 1), o lote 1 obteve maior porcentagem de plântulas normais, enquanto que os lotes 2, 3, 4 e 5 apresentaram a menor porcentagem. A primeira contagem do teste de germinação apresentou resultados semelhantes aos obtidos pelo teste de emergência das plântulas em campo.

A avaliação do teste de envelhecimento acelerado destacou

TABELA1. Plântulas normais obtidas na primeira contagem e contagem final do teste de germinação, de envelhecimento acelerado, de frio modificado, de emergência das plântulas em campo e condutividade elétrica, em cinco lotes de sementes de milho.

\begin{tabular}{|c|c|c|c|c|c|c|}
\hline Lotes $^{1}$ & $\begin{array}{c}\text { Emergência das } \\
\text { plântulas em campo }\end{array}$ & $\begin{array}{l}\text { Primeira contagem do } \\
\text { teste de germinação }\end{array}$ & Germinação & $\begin{array}{c}\text { Envelhecimento } \\
\text { acelerado }\end{array}$ & $\begin{array}{l}\text { Teste de frio } \\
\text { modificado }\end{array}$ & $\begin{array}{c}\text { Condutividade } \\
\text { elétrica } \\
\mu \mathrm{Scm}^{-1} \mathrm{~g}^{-1}\end{array}$ \\
\hline 1 & $72 \mathrm{~A}$ & $88 \mathrm{~A}$ & $93 \mathrm{~A}$ & $62 \mathrm{~A}$ & $84 \mathrm{~A}$ & $14,88 \mathrm{~B}$ \\
\hline 2 & $59 \mathrm{~B}$ & $78 \mathrm{~B}$ & $87 \mathrm{~B}$ & $64 \mathrm{~A}$ & $85 \mathrm{~A}$ & $13,27 \mathrm{~B}$ \\
\hline 3 & $63 \mathrm{~B}$ & $77 \mathrm{~B}$ & $86 \mathrm{~B}$ & $66 \mathrm{~A}$ & $84 \mathrm{~A}$ & $27,39 \mathrm{~A}$ \\
\hline 4 & $59 \mathrm{~B}$ & $76 \mathrm{~B}$ & $90 \mathrm{~A}$ & $62 \mathrm{~A}$ & $78 \mathrm{~B}$ & $15,25 \mathrm{~B}$ \\
\hline 5 & $36 \mathrm{C}$ & $79 \mathrm{~B}$ & $92 \mathrm{~A}$ & $34 \mathrm{~B}$ & $82 \mathrm{~A}$ & $14,26 \mathrm{~B}$ \\
\hline Média & 58,07 & 79,85 & 89,73 & 57,43 & 82,60 & 17,01 \\
\hline C.V. $(\%)$ & 7,83 & 5,34 & 4,51 & 6,76 & 5,94 & 23,61 \\
\hline
\end{tabular}

${ }^{1}$ Médias seguidas de mesma letra, em cada coluna, pertencem a um mesmo grupo, de acordo com o critério de agrupamento de Scott-Knott (1974), a 5\% de probabilidade. 
os lotes 1, 2, 3 e 4 como os mais vigorosos e o lote 5 como o de menor vigor. Estes resultados estão de acordo com o teste de emergência das plântulas em campo, em que o lote 5 apresentou-se um potencial fisiológico significativamente inferior aos demais lotes (Tabela 1).

No teste de frio modificado (Tabela 1), os lotes 1, 2, 3 e 5 apresentaram maior porcentagem de plântulas normais, sendo os mais vigorosos; enquanto que o lote 4 apresentou menor porcentagem de plântulas normais no referido teste, sendo o de menor potencial fisiológico. O teste de frio é considerado pela Internacional Seed Testing Association (ISTA, 1981) e Association of Official Seed Analysts (AOSA, 1983) como um dos mais importantes na avaliação da qualidade de sementes de milho. Segundo Grabe (1976), os lotes de qualidade adequada devem apresentar, no mínimo, 70 a $80 \%$ de plântulas normais como resultado do teste de frio; valores estes observados em todos os lotes. Schuab (2003) verificou que o teste de frio modificado não apresentou resultados consistentes, não sendo, portanto, confiável na avaliação da qualidade fisiológica das sementes de soja. $\mathrm{O}$ teste de frio segundo Medina e Marcos Filho (1990) detecta diferenças de qualidade das sementes apenas quando estas são acentuadas.

O teste de condutividade elétrica indicou o lote 3 como o que lixiviou mais solutos, constituindo-se como de baixa qualidade fisiológica; por outro lado, os lotes 1, 2, 4, 5 apresentaram menor taxa de lixiviação de solutos, revelando serem lotes de melhor qualidade fisiológica. De acordo com Dias e Marcos Filho (1996), os maiores valores de lixiviação de solutos correspondem as menores porcentagens de plântulas normais como resultado desse teste, o que não foi verificado para o lote 2 , com relação aos resultados obtidos no teste de germinação. Dessa forma, o teste de condutividade elétrica apresentou sensibilidade variável ao diferenciar a qualidade fisiológica dos diferentes lotes de milho avaliados (Tabela 1). As mesmas informações não foram obtidas por Schuab (2003), em que esta autora verificou que o teste de condutividade elétrica foi suficiente para diferenciar a qualidade fisiológica de dez genótipos de soja e que os resultados do referido teste concordou com os resultados obtidos nos testes de emergência em campo e de germinação (primeira contagem e última contagem). Resultados semelhantes foram obtidos por Ávila (2003), porém trabalhando com diferentes lotes de sementes de canola.

Com base nos resultados dos valores médios do comprimento total das plântulas para os diferentes lotes de sementes de milho, em cada nível de potencial osmótico, constatou-se para as sementes do grupo controle (água), apenas o lote 5 diferiu significativamente dos demais, apresentando menor comprimento das plântulas; o mesmo resultado pode ser observado no potencial -0,3MPa. Em contrapartida, nos potenciais de -0,1MPa; -0,6MPa e -0,9MPa houve uma resposta diferenciada para cada lote, destacandose os resultados obtidos no nível de potencial de -0,9MPa que apresentaram os resultados similares ao do teste de emergência das plântulas em campo. De uma foram geral, os níveis de potencial de -0,3MPa; -0,6MPa e -0,9MPa restringiram o comprimento das plântulas, para todos os lotes avaliados (Tabela 2). Segundo Silva (1989), em geral, a baixa disponibilidade de água reduz o comprimento das plântulas de milho.

A avaliação do comprimento das plântulas sob estresse hídrico, para cada lote em função dos níveis de potencial osmótico utilizados, embora não tenha sido possível precisar um ajuste matemático, observou-se que o comprimento das plântulas de milho de todos os lotes testados apresentaram a

TABELA 2. Valores médios do teste de comprimento das plântulas (cm) sob estresse hídrico obtidos nos diferentes níveis de potencial osmótico, em cinco lotes de sementes de milho.

\begin{tabular}{llllll}
\hline \multirow{2}{*}{ Lotes $^{1}$} & \multicolumn{5}{c}{ Potencial osmótico (MPa) } \\
\cline { 2 - 6 } & 0 & $-0,1$ & $-0,3$ & $-0,6$ & $-0,9$ \\
\hline 1 & $49,18 \mathrm{~A}$ & $54,45 \mathrm{~A}$ & $38,95 \mathrm{~A}$ & $20,99 \mathrm{~A}$ & $22,03 \mathrm{~A}$ \\
2 & $46,55 \mathrm{~A}$ & $54,78 \mathrm{~A}$ & $36,60 \mathrm{~A}$ & $17,98 \mathrm{~B}$ & $17,87 \mathrm{~B}$ \\
3 & $47,24 \mathrm{~A}$ & $49,19 \mathrm{~B}$ & $38,34 \mathrm{~A}$ & $20,61 \mathrm{~A}$ & $17,56 \mathrm{~B}$ \\
4 & $47,93 \mathrm{~A}$ & $53,58 \mathrm{~A}$ & $38,93 \mathrm{~A}$ & $21,04 \mathrm{~A}$ & $18,87 \mathrm{~B}$ \\
5 & $43,65 \mathrm{~B}$ & $49,78 \mathrm{~B}$ & $31,58 \mathrm{~B}$ & $15,50 \mathrm{C}$ & $14,96 \mathrm{C}$ \\
\hline Média & 46,91 & 52,36 & 36,88 & 19,22 & 18,26 \\
\hline C.V. $(\%)$ & 10,05 & 9,35 & 12,12 & 17,19 & 13,08 \\
\hline
\end{tabular}

${ }^{1}$ Médias seguidas de mesma letra, em cada coluna, pertencem a um mesmo grupo, de acordo com o critério de agrupamento de Scott-Knott (1974), a 5\% de probabilidade. 
mesma tendência de crescimento, quando submetidos a diferentes níveis de estresse hídrico. Como observado na Figura 1, o comportamento de crescimento das plântulas de milho para todos os lotes, no potencial osmótico de -0,1MPa, foi maior em relação ao controle (zero MPa), isto ocorreu possivelmente porque há um maior crescimento do sistema radicular a procura de água em maiores profundidades.

O aumento no potencial osmótico de -0,3Mpa a -0,9MPa ocasionou um decréscimo gradual significativo no comprimento das plântulas de milho fato confirmado por Machado Neto et al., (2004) em sementes de soja, utilizando soluções de manitol e de $\mathrm{NaCl}$.

A resposta das sementes colocadas para germinar sob deficiência hídrica tem se mostrado dependente da qualidade fisiológica. De um modo geral, menores qualidades fisiológicas têm sido associadas a piores desempenhos (Mathews e Powell, 1986) o que pode ser observado para o lote 5.

Os resultados obtidos nesse trabalho, indicaram o lote 1 como o que apresentou maior germinação e vigor das suas sementes em todos os testes avaliados, inclusive nos diferentes níveis de potencial osmótico do teste de comprimento das plântulas sob estresse hídrico (Tabelas 1 e 2).

A análise da correlação entre os resultados obtidos no laboratório com a emergência das plântulas em campo está representada na Tabela 3. Com relação aos resultados, destacase o valor de correlação $\left(r=0,5951^{*}\right)$ obtido entre o teste de envelhecimento acelerado e a emergência das plântulas em campo como o mais elevado. Resultados obtidos por Torres (1998a) trabalhando com sementes de milho, destacaram o valor de correlação obtido entre o teste de frio sem solo e a emergência em campo como o mais elevado.

$O$ teste de frio modificado correlacionou-se significamente apenas com o teste de emergência das plântulas em campo e com a primeira contagem de germinação. Resultados similares foram obtidos novamente por Torres (1997), porém com sementes de sorgo. Os testes de germinação e de condutividade elétrica não obtiveram correlação significativa com praticamente nenhum nível de potencial osmótico de manitol (exceto da C.E. com -0,1MPa), inclusive com a emergência das plântulas em campo. Torres (1998a e 1998b), trabalhando com sementes de milho e cebola, obteve correlação significativa entre o teste de condutividade elétrica e o teste de emergência das plântulas em campo.

Por meio dos resultados da análise de correlação entre o teste de emergência das plântulas em campo com o teste de comprimento das plântulas sob estresse hídrico, verificou-se correlação significativa desse teste com todos os níveis de potenciais osmótico avaliados nesse trabalho, ou seja, zero MPa $(r=0,2384 *),-0,1 \mathrm{MPa}\left(\mathrm{r}=0,2115^{*}\right),-0,3 \mathrm{MPa}(\mathrm{r}=$ $\left.0,4087^{*}\right),-0,6 \mathrm{MPa}\left(\mathrm{r}=0,3403^{*}\right)$ e $-0,9 \mathrm{MPa}\left(\mathrm{r}=0,4897^{*}\right)$. Estes resultados indicam a eficiência do teste de comprimento das plântulas sob estresse hídrico na avaliação do potencial fisiológico das sementes de milho. Cabe ressaltar que o nível de -0,9MPa destacou-se dos demais por obter o maior valor

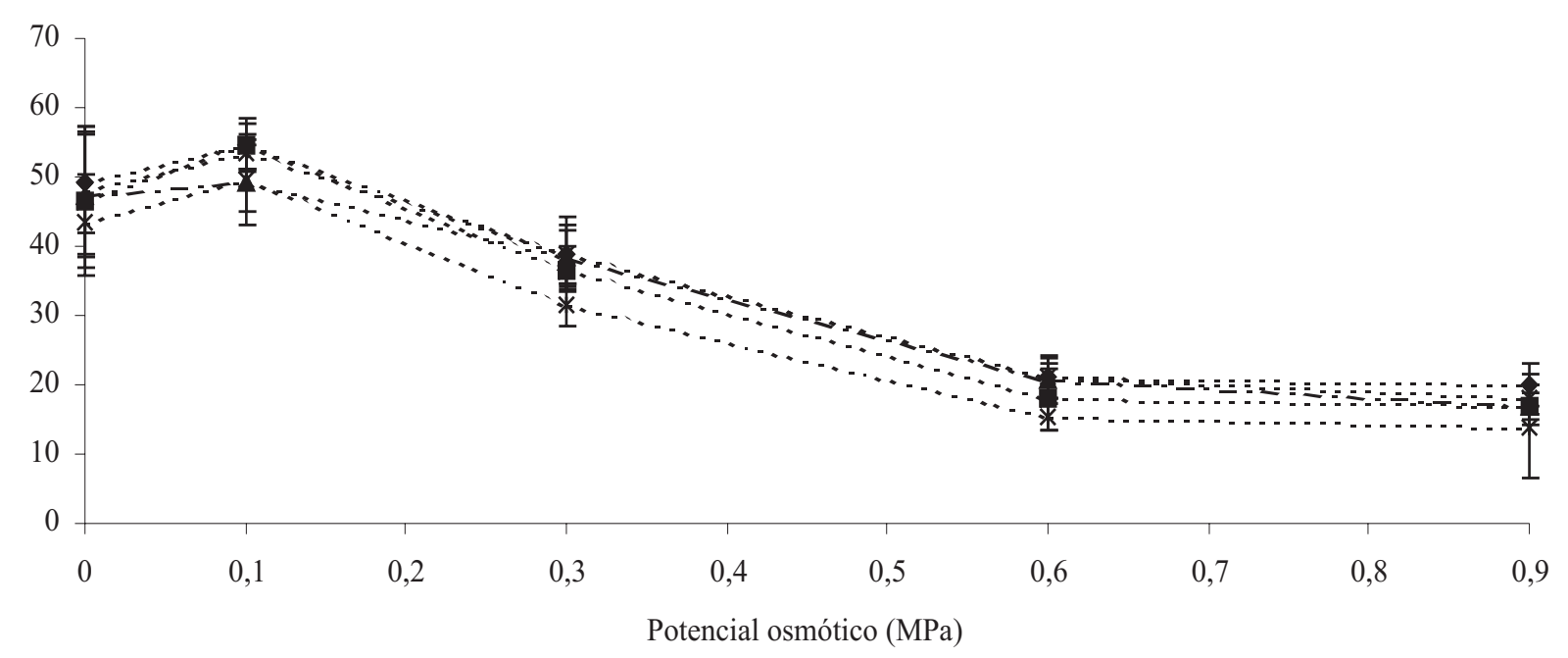

... - . Lote 1 . . . . . Lote 2 - - - - - Lote $3 \ldots \times$. . Lote $4 \ldots$. . . Lote 5

FIGURA 1. Comprimento das plântulas em cinco lotes de sementes de milho submetidas a diferentes níveis de potencial osmótico em soluções de manitol. 
TABELA 3. Coeficientes de correlação simples de Pearson (r) estimados entre os testes de avaliação da qualidade fisiológica das sementes e o teste de comprimento das plântulas sob estresse hídrico e a emergência das plântulas em campo, obtidos com base na média dos cinco lotes de sementes de milho.

\begin{tabular}{|c|c|c|c|c|c|c|c|c|c|c|}
\hline & GERM. & C.E. & ENV. & F.M. & CONTR. & $-0,1 \mathrm{MPa}$ & $-0,3 \mathrm{MPa}$ & $-0,6 \mathrm{MPa}$ & $-0,9 \mathrm{MPa}$ & E.P.C. \\
\hline PCG. ${ }^{1}$ & $0,6879^{*}$ & $-0,2423^{*}$ & $0,0242^{\mathrm{ns}}$ & $0,2810^{*}$ & $0,0784^{\mathrm{ns}}$ & $0,0968^{\mathrm{ns}}$ & $0,1822^{*}$ & $0,1152^{\mathrm{ns}}$ & $0,3664^{*}$ & $0,3649^{*}$ \\
\hline GERM. & & $-0,2980^{*}$ & $0,2648^{*}$ & $0,0093^{\mathrm{ns}}$ & $0,1463^{\mathrm{ns}}$ & $0,0949^{\mathrm{ns}}$ & $0,0834^{\mathrm{ns}}$ & $0,0599^{\mathrm{ns}}$ & $0,1627^{\mathrm{ns}}$ & $0,0621^{\mathrm{ns}}$ \\
\hline C.E. & & & $-0,2542^{*}$ & $-0,0290^{\mathrm{ns}}$ & $-0,0460^{\mathrm{ns}}$ & $-0,2253^{*}$ & $-0,1167^{\mathrm{ns}}$ & $0,1745^{*}$ & $-0,0180^{\mathrm{ns}}$ & $0,1381^{\mathrm{ns}}$ \\
\hline ENV. & & & & $0,1449^{\mathrm{ns}}$ & $0,0935^{\mathrm{ns}}$ & $0,2774^{*}$ & $0,4963^{*}$ & $0,4821^{*}$ & $0,3887^{*}$ & $0,5951^{*}$ \\
\hline F.M. & & & & & $0,0915^{\mathrm{ns}}$ & $0,0503^{\mathrm{ns}}$ & $0,1466^{\mathrm{ns}}$ & $0,0238^{\mathrm{ns}}$ & $0,3340^{\mathrm{ns}}$ & $0,3213^{*}$ \\
\hline CONTR. & & & & & & $0,1711^{\mathrm{ns}}$ & $0,1020^{\mathrm{ns}}$ & $0,2929^{*}$ & $0,3313^{*}$ & $0,2384^{*}$ \\
\hline$-0,1 \mathrm{MPa}$ & & & & & & & $0,0562^{\mathrm{ns}}$ & $0,2105^{*}$ & $0,1571^{\mathrm{ns}}$ & $0,2115^{*}$ \\
\hline$-0,3 \mathrm{MPa}$ & & & & & & & & $0,2463^{*}$ & $0,3043^{*}$ & $0,4087^{*}$ \\
\hline$-0,6 \mathrm{MPa}$ & & & & & & & & & $0,3387^{*}$ & $0,3403^{*}$ \\
\hline$-0,9 \mathrm{MPa}$ & & & & & & & & & & $0,4897^{*}$ \\
\hline
\end{tabular}

${ }^{1}$ PCG. = primeira contagem de germinação; GERM. = germinação; C.E. = condutividade elétrica; ENV. = envelhecimento acelerado; F.M. = frio modificado; CONTR. = comprimento de plântulas sob estresse hídrico no potencial de zero MPa ; -0,1MPa = comprimento de plântulas sob estresse hídrico no potencial de -0,1MPa; -0,3MPa = comprimento de plântulas sob estresse hídrico no potencial de -0,3MPa; -0,6MPa = comprimento de plântulas sob estresse hídrico no potencial de - 0,6MPa; -0,9MPa = comprimento de plântulas sob estresse hídrico no potencial de -0,9MPa; E.P.C. = emergência das plântulas em campo.

* = r significativo a $5 \%$ de probabilidade; ${ }^{\text {ns }}=\mathrm{r}$ não significativo.

de correlação significativa. Torres (1998a), trabalhando com sementes de milho, considerou a avaliação do comprimento das plântulas sob estresse hídrico a -0,6MPa como indicativo para a avaliação do vigor de sementes de milho, já que apresentou alta correlação com a emergência das plântulas em campo.

Os resultados obtidos nesse trabalho estão de acordo com Piana e Silva (1998) que observaram em situações de deficiência hídrica que o desenvolvimento das plântulas foi menor durante a germinação das sementes de milho, sendo as sementes mais vigorosas, as que, apresentam desempenho superior quando submetidas a esta condição.

\section{CONCLUSÕES}

O teste de comprimento das plântulas sob estresse hídrico a -0,9MPa é o mais eficiente para avaliar o potencial fisiológico de sementes de milho.

O teste de comprimento das plântulas sob estresse hídrico pode ser utilizado para avaliar o potencial fisiológico de sementes de milho com potenciais a partir de -0,3MPa.

Há uma correlação significativa e positiva entre o teste de comprimento de plântulas sob estresse hídrico e a emergência das plântulas em campo.

\section{REFERÊNCIAS}

ÁVILA, M. R. Qualidade fisiológica das sementes de canola (Brassica napus L. var. oleifera Metzg.) sob influência do condicionamento osmótico e da adubação com potássio. Capítulo
I - Qualidade fisiológica das sementes de canola e sua relação com a emergência das plântulas no campo. 2003. 115f. Dissertação (Mestrado em Agronomia) - Universidade Estadual de Maringá, Maringá, 2003.

ASSOCIATION OF OFFICIAL SEED ANALYSTS. Seed Vigor Test Committee. Seed testing handbook. Lincoln, 1983. 88p. (Contribution, 32).

BARROS, A.S.R; DIAS, M.C.L.L.; CÍCERO, S.M.; KRZYZANOWSKI, F.C. Teste de frio. In: KRZYZANOWSKI, F.C.; VIEIRA, R.D.; FANÇA NETO, J.B. (Ed.). Vigor de sementes: conceitos e testes. Londrina: ABRATES, 1999. p.5.1-5.13.

BRACCINI, M.C.L.; BRACCINI, A.L; DIAS, D.C.F.S.; ALVARENGA, E.M.; RUIZ, H.A. Efeito do potencial hídrico no solo e no substrato embebido com manitol sobre a germinação de sementes de soja. Revista Brasileira de Sementes, Brasília, v.18, n. 2, p.200-207, 1996b.

BRASIL. Ministério da Agricultura e da Reforma Agrária. Regras para análise de sementes. Brasília: SNDA/DNDV/CLAV, 1992. 365p.

BYRUM, J. R.; COPELAND, L. O. Variability in vigour testing of maize (Zea mays L.) seed. Seed Science and Technology, Zürich, v.23, n. 2, p.543-549, 1995.

CALIARI, M.F.; SILVA, W.R. Interpretação de dados de testes de vigor na avaliação da qualidade fisiológica de sementes de milho. Revista Brasileira de Sementes, Brasília, v.23, n.1, p.239251, 2001.

DIAS, D.C.F.S.; MARCOS FILHO, J. Testes de condutividade elétrica para avaliação do vigor de sementes de soja (Glycine $\max ($ L.) Merrill). Scientia Agricola, Piracicaba, v.53, n.1, p.31-42, 1996.

EMMERICH, W.E.; HARDEGREE, S.P. Seed germination in polyethylene glycol solution: effects of filter paper exclusion and water vapor loss. Crop Science, Madison, v.31, n.2, 
p.454-458, 1991.

FERGUSON-SPEARS, J. An introduction to seed vigour testing. In: VAN DE VENTER, H.A. (Ed.). Seed vigour testing seminar. Zürich: ISTA, 1995. p.1-10.

GERMU, M.; NAYLOR, R.E.L. Effects of low water availability on germination of two sorghum cultivars. Seed Science and Technology, Zürich, v.19, n.2, p.373-383, 1991.

GRABE, D.F. Measurement of seed vigor. Journal of Seed Technology, Springfield, v.1, n.2, p.18-31, 1976.

HILLEL, D. Soil and water. Physical principies and processes. New York: Academic Press, 1971. 288p.

INTERNATIONAL SEED TESTING ASSOCIATION. Handbook of vigour test methods. Zürich: ISTA, 1981. 72p.

MACHADO NETO, N.B.A.; CUSTÓDIO, C.C.; COSTA, P.R.; DONÁ, F.L. Deficiência hídrica induzida por diferentes agentes osmóticos na germinação e vigor de sementes de feijão. Revista Brasileira de Sementes, Brasília, v.1, n.28, p.142 - 148, 2006.

MACHADO NETO, N.B.; SATURNINO, S.M.; BOMFIM, D.C.; CUSTÓDIO, C.C. Water stress induced by mannitol and sodium chloride in soybean cultivars. Brazilian Archives of Biology and

Technology, Curitiba, v.47, n.4, p. 521-529, 2004.

MARCOS FILHO, J. Testes de vigor: importância e utilização. In: KRZYZANOWSKI, F.C.; VIEIRA, R.D.; FANÇA NETO, J.B. (Ed.). Vigor de sementes: conceitos e testes. Londrina: ABRATES, 1999a. p.1.1-1.21.

MARCOS FILHO, J. Teste de envelhecimento acelerado. In: KRZYZANOWSKI, F.C.; VIEIRA, R.D.; FANÇA NETO, J.B. (Ed.). Vigor de sementes: conceitos e testes. Londrina: ABRATES, 1999b. p. 3.1-3.24.

MARCOS FILHO, J.; PESCARIN, H.M.C.; KOMATSU, Y.H.; DEMÉTRIO, C.G.B.; FANCELLI, A.L. Testes para avaliação do vigor de sementes de soja e sua relação com a emergência das plântulas em campo. Pesquisa Agropecuária Brasileira, Brasília, v.19, n.5, p.605-613, 1984.

MATHEWS, S.; POWELL, A.A. Environmental and physiological constraints on field performance of seeds. HortScience, Alexandria, v.21, n.5, p.1125-1128, 1986.

McDONALD JUNIOR, M.B.; WILSON, D.O. An assessment of the standardization and ability of the ASA-610 to rapidly predict potential soybean germination. Journal of Seed Technology, Springfield, v.4, n.2, p.1-11, 1979.

McDONALD JUNIOR, M.B. The history of seed vigour testing. Journal of Seed Technology, Zürich, v.17, n.2, p.93-100, 1993.

MEDINA, P.F., MARCOS FILHO, J. Avaliação da qualidade fisiológica de sementes de milho (Zea mays L.). Anais da Escola Superior de Agricultura "Luiz de Queiroz", Piracicaba, v.47, n.1, p.47-70, 1990.

NAKAGAWA, J. Testes de vigor baseados na avaliação das plântulas. In: VIEIRA, R.D.; CARVALHO, N.M. (Ed.). Testes de vigor em sementes. Jaboticabal: FUNEP, 1994. 164p.

NAKAGAWA, J. Testes de vigor baseados no desempenho das plântulas. In: KRZYZANOWSKI, F.C.; VIEIRA, R.D.; FANÇA NETO, J.B. (Ed.). Vigor de sementes: conceitos e testes. Londrina: ABRATES, 1999. p.2.1-2.24.

PARMAR, M.T.; MOORE, R.P. Carbowax 6000, mannitol and sodium chloride for simulating drought conditions in germination studies of corn (Zea mays L.) of strong and weak vigor. Agronomy Journal, Madison, v.60, n.1, p.192-195, 1968.

PIANA, Z.; SILVA, W.S. Respostas de sementes de milho, com diferentes níveis de vigor, à disponibilidade hídrica. Pesquisa Agropecuária Brasileira, Brasília, v.33, n.9, páginas?, 1998.

SANTOS, V.L.M.; SILVA, R.F.; SEDIYAMA, T.; CARDOSO, A.A. A utilização do estresse osmótico na avaliação do vigor de sementes de soja (Glycine max (L.) Merrill). Revista Brasileira de Sementes, Brasília, v.18, n.1, p.83-87, 1996.

SCHUAB, S. R. P. Avaliação da qualidade fisiológica das sementes de soja por meio da taxa de crescimento das plântulas e do teste de germinação sob estresse hídrico. 2003. 80f. Tese (Doutorado em?) - Faculdade?, Universidade Estadual de Maringá, Maringá, 2003.

SCOTT, A.; KNOTT, M. Cluster-analysis method for grouping means in analysis of variance. Biometrics, Washington D.C., v.30, n.3, p.507-512, 1974.

SILVA, W.R. Relações entre disponibilidade de água, tratamento fungicida e germinação de sementes de milho (Zea mays L.). 1989. 113p. Tese (Doutorado em Fitotecnia) - Escola Superior de Agricultura “Luiz de Queiroz”, Universidade de São Paulo, Piracicaba, 1989.

SOUZA, G.M.; CARDOSO, V.J.M. Effects of different environmental stress on seed germination. Seed Science Technology, Zürich, v.28, n.3, p.621-630, 2000.

SLAVIK, B. Methods of studing plant water relations. New York: Springer-Verlag, 1974. 449p.

TORRES, S.B. Qualidade fisiológica de sementes de sorgo através do teste de estresse hídrico. Ciência Rural, Santa Maria, v.27, n.1, p.31-35, 1997.

TORRES, S.B. Testes de vigor na avaliação da qualidade fisiológica de sementes de milho. Revista Brasileira de Sementes, Brasília, v.20, n.1, p.55-59, 1998a.

TORRES, S.B. Comparação entre diferentes testes de vigor e a correlação com a emergência no campo de sementes de cebola. Revista Brasileira de Sementes, Brasília, v.20, n.1, p.65-69. 1998b.

VIEIRA, R.D.; KRZYZANOWSKI, F.C. Teste de condutividade elétrica. In: KRZYZANOWSKI, F.C.; VIEIRA, R.D.; FANÇA NETO, J.B. (Ed.). Vigor de sementes: conceitos e testes. Londrina: ABRATES, 1999. p.4.1-4.26.

YOUNG, J.A.; EVANS, R.A.; ROUNDY, B.; CLUFF, G. Moisture stress and seed germination. Oakland: USDA/ARS, 1983. 41p. (Agricultural Reviews and Manuals. Western Series, 36). 